\title{
Promovendo um espaço para informação sobre a Estratégia Saúde da Família: um relato de experiência
}

\author{
Promoting a field for information concerning strategy in Family \\ Health Strategy: an experience report
}

Isabela Barboza da Silva Tavares Amaral1

\begin{abstract}
RESUMO A realidade nas unidades de Atenção Básica aponta para usuários do Sistema Único de Saúde que não conhecem plenamente a Estratégia Saúde da Família. O objetivo do presente artigo é relatar a experiência da criação de um grupo de Educação Popular em Saúde, que buscou ampliar o acesso às informações aos usuários. Este trabalho consiste em um estudo descritivo, no qual se buscou pontuar o caminho percorrido do planejamento à execução da atividade e descrever o encontro realizado. É preciso que haja comprometimento com a educação popular, para que então se alcancem melhores resultados no fortalecimento do controle social, nos cuidados mais efetivos e nas gestões mais democráticas.
\end{abstract}

PALAVRAS-CHAVEEstratégia Saúde da Família; Atenção Primáriaà Saúde; Participação comunitária.

ABSTRACT The reality is that users of Unified Health System are still not fully familiar with the Family Health Strategy. The aim of this paper is to report the experience of creating a Popular Education in Health group, with the purpose of expanding access to information to users. This work is a descriptive study, in which we sought to explain how the process happened from the planning to the execution of the activity, and describe the encounter that occurred. There must be engagement with Popular Education, so that we reach better results in the strengthening of the social control, in more effective care, and in the democratic administrations.

KEYWORDS Family Health Strategy; Primary Health Care; Consumer participation.

1 Universidade Federal 


\section{Introdução}

No mundo, onde a informação está cada vez mais acessível às pessoas, independentemente do meio cultural ou nível socioeconômico ocupado por elas, torna-se uma violação aos direitos do cidadão ter um conhecimento limitado quanto ao funcionamento do sistema de saúde em que ele está inserido.

Segundo Mendes (1996), por se tratar de uma reforma social que ocorre em um cenário democrático e que requer certa transformação cultural, o Sistema Único de Saúde (SUS) possui um caráter processual de maturação lenta. Entendendo o SUS por esse aspecto, cabe aos cidadãos monitorar esse 'processo de maturação’ e garantir a continuidade dele, não adotando uma postura pessimista ante a lentidão dos passos rumo à efetivação plena do sistema, mas sim assumindo um papel de participação ativa que deve coparticipar com contribuições construtivas para promoção de ações, com vistas à operacionalização do que é proposto nas políticas e programas que regem o funcionamento do SUS no Brasil.

Uma das práticas humanizadoras que o Ministério da Saúde apresenta na proposta do HumanizaSUS é a ampliação dos mecanismos de comunicação e informação. Ele enfatiza, também, a necessidade do desenvolvimento da gestão participativa nas instituições públicas de saúde, envolvendo trabalhadores e usuários na tomada de decisão dos atos de gestão. Nesse sentido, cabe ressaltar que a produção de cuidado deve estar ligada à geração de espaços de comunicação efetiva.

Entende-se que o cuidado envolve diversos aspectos de prevenção de doenças, proteção, reabilitação e promoção da saúde do indivíduo. A promoção de saúde está diretamente vinculada à obtenção das informações necessárias para o ganho de autonomia do indivíduo diante das diversas situações de vida diária, que apresentam potencial para interferir na determinação de sua saúde.

A garantia do acesso à informação sobre o funcionamento dos serviços de saúde é dada judicialmente pelo Art. $7^{\circ}$ da Portaria 1.829 , de 13 de agosto de 2009 (BRASIL, 2009), e garantida no Art. $7^{\circ}$ da Lei ${ }^{\circ}$ 8.080, de 19 de setembro de 1990 (BRASIL, 1990). Já a Lei no 8.142/90 dispõe sobre a participação da comunidade na gestão do SUS.

Entretanto, é fácil perceber que a realidade em muitas cidades do Brasil aponta para a existência de usuários do SUS que não possuem o conhecimento sobre o sistema e sobre o novo modelo de atenção que vivenciam, em que a Atenção Básica ( $A B$ ) surge enquanto ordenadora do sistema.

Para Fonseca et al. (2012), a carência de informações da população acerca do SUS, principalmente no que se refere à participação popular, é resultado da ausência de investimento em práticas comunitárias que sejam solidárias ao enfrentamento dos problemas de saúde.

A educação em saúde é uma prática de caráter transversal que permite a configuração de uma política de saúde de forma compartilhada (BRASIL, 2007), sendo essencial no que tange às ações que acontecem na relação direta dos serviços com os usuários, além de ser imprescindível para viabilização do controle social no SUS. Afinal, que tipo de 'controle' poderá ser exercido por cidadãos pouco informados a respeito do funcionamento das políticas públicas de saúde? $\mathrm{Ou}$, simplesmente, sobre o funcionamento básico da Estratégia Saúde da Família (ESF)?

As práticas de fomento à participação popular no sistema público de saúde fazem parte da configuração de uma real democracia. Para Rolim, Cruz e Sampaio (2013), a garantia dessa participação em todas as esferas de gestão do SUS pode ser considerada uma forma mais avançada de democracia, pois redefine as relações entre Estado e sociedade.

Nesse sentido, a educação popular destaca-se como instrumento de grande potencial para concretização dos princípios e diretrizes do SUS, visto que permite a problematização de uma mesma realidade vivida. A base da educação popular consiste em "uma 
conjunção de saberes, de vivências e de práticas que apresentam, em comum, a negação da situação existente e a construção do inédito viável” (BONETTI; PEDROSA; SIQUEIRA, 2011, P. 398).

Sendo assim, é muito importante que haja o desenvolvimento de tais práticas por profissionais da ESF, pois o vínculo que se espera estar constituído entre estes e os usuários da unidade permite ações de maior impacto na comunidade, promovendo a apropriação da saúde enquanto direito por parte da população e contribuindo para a configuração de espaços democráticos de informação.

Experiências que buscam o incentivo à autonomia da comunidade nas ações de controle social e na integração do serviço à comunidade têm sido descritas em muitos trabalhos (BARRETO ET AL., 2012). Quanto maior é o alcance da expansão da ESF em território nacional, mais pode ser sentida a necessidade da reprodução dessas experiências nas unidades, enquanto profissionais de saúde, pois a corresponsabilização na construção da $\mathrm{AB}$ à saúde, como coordenadora do cuidado, conforme defende Starfield (2002), só poderá se consolidar a partir de ações que promovam conhecimento à população e, portanto, a formação de cidadãos engajados nesse processo.

Quando não há comunicação efetiva entre profissional-usuário, o cuidado se torna uma imposição. Essa afirmação tanto serve para procedimentos ou tratamentos instituídos nos consultórios como para as políticas públicas de saúde e os modelos de atenção, uma vez que todos são desenvolvidos visando à viabilização do cuidado integral ao indivíduo.

Desse modo, é preciso apreender o sentido do que defende Pedrosa e Pereira (2007), quando inferem que o serviço de saúde precisa estar integrado de fato a todo modo de vida que o cerca, para que possa então concretizar sua missão. Enquanto essa ideia não for tomada como premissa fundamental de trabalho, todos os esforços na direção do estabelecimento de um cuidado integral, por meio da concretização das políticas de saúde, serão em vão. Já se avançou muito quanto ao entendimento de que nenhum tratamento pode ser eficaz se o usuário não compreender a importância de seguir as orientações do profissional de saúde, mas talvez ainda se tenha muito a progredir quanto ao entendimento de que ele precisa, também, englobar o funcionamento do sistema de saúde, bem como os novos direcionamentos de suas políticas de atenção.

É finalidade deste trabalho relatar a experiência da criação de um grupo de Educação Popular em Saúde, cujo espaço tem por finalidade a disseminação de informação e a troca de saberes sobre o funcionamento da ESF.

\section{Método}

Esta pesquisa consiste em um relato de experiência acerca da realização de um grupo de Educação Popular em Saúde, no qual se buscou pontuar o caminho percorrido do planejamento à execução da atividade, descrever o encontro sucedido, bem como a percepção dos profissionais de saúde que idealizaram o grupo, quanto à importância da criação de espaços como estes nas unidades de saúde da família. Este trabalho foi realizado em uma Clínica de Saúde da Família, localizada na cidade do Rio de Janeiro, que atende a uma comunidade de cerca de 24 mil pessoas cadastradas, onde uma enfermeira e um dentista se propuseram a reunir usuários com vistas ao esclarecimento de conceitos básicos sobre os princípios do SUS, as diretrizes da $\mathrm{AB}$ e o funcionamento da ESF.

O modelo conceitual que orientou o trabalho dos profissionais no grupo foi baseado nas concepções teóricas de Paulo Freire (2002), principalmente no que tange ao respeito dos saberes construídos socialmente na prática comunitária, criando-se a possibilidade de discutir a razão de ser de alguns desses saberes. Conforme esse mesmo autor, "um dos equívocos funestos de militantes políticos de prática messianicamente autoritária foi sempre desconhecer totalmente a 
compreensão do mundo dos grupos populares" (FREIRE, 2002, P. 32).

Após a realização dos grupos, os profissionais responsáveis pelo desenvolvimento deles se reuniam para refletir sobre cada encontro.

Este artigo foi estruturado em quatro momentos: o primeiro se refere a uma breve caracterização da $\mathrm{AB}$ na cidade do Rio de Janeiro; o segundo narra o caminho percorrido pelos profissionais durante o planejamento do grupo; o terceiro descreve a operacionalização do grupo; e o quarto descreve as reflexões geradas após vivência dessa experiência pelos profissionais de saúde à luz da pedagogia proposta por Paulo Freire.

\section{Breve caracterização da Atenção Básica no Rio de Janeiro}

No Brasil, tem-se percebido certos ganhos na qualidade de vida da população após a implantação da ESF, como é possível verificar com os resultados da sua expansão no município do Rio de Janeiro, principalmente, entre 2010 e 2011, onde a estratégia recebeu um incremento de aproximadamente $15 \%$. A importância da ESF na reorientação do modelo assistencial tornou-se clara com a queda nas internações hospitalares (quase 17 mil internações a menos entre janeiro e outubro de 2010), o que inclui as internações por doenças cardiovasculares, e "visível redução, ainda a quantificar, da demanda de atendimento de urgência, graves pontos de estrangulamento do modelo assistencial ainda hegemônico" (RODRIGUES; ANDERSON, 2011, P. 22). Na cidade do Rio de Janeiro, muito se investe no fortalecimento da $\mathrm{AB}$ por meio da expansão da ESF.

Nessa cidade, as unidades tradicionais de $A B$ eram em sua totalidade os Centros Municipais de Saúde (CMS). Entretanto, essa transição do modelo tradicional de $\mathrm{AB}$ ofertado pelos CMS, para o modelo em que essa atenção é ofertada pela ESF, muitas vezes se torna gerador de tensões na relação usuário-profissional. É comum perceber que usuários que não compreendem o funcionamento da ESF tendem a ter resistência a ela, devido a alta prevalência na cultura popular do modelo biomédico de caráter medicalizante e gerador de uma atenção fragmentada focada no atendimento especializado.

Causa certo estranhamento na população uma unidade onde os enfermeiros fazem consulta, acompanham pré-natais e realizam a coleta do exame citopatológico uterino, onde os médicos generalistas cuidam da diabetes sem encaminhar ao endocrinologista e onde esses médicos também fazem o acompanhamento de crianças sem encaminhar, necessariamente, ao pediatra.

Desse cenário, emerge a necessidade da criação de espaços dentro das Unidades Básicas de Saúde (UBS) ou dentro da própria comunidade que promovam a educação popular com vistas a dialogar sobre a ESF.

\section{Planejamento do grupo de Educação Popular em Saúde}

Profissionais da ESF mencionam ser constantes os questionamentos da população acerca da ausência de especialistas, das consultas de enfermagem, do funcionamento do Sistema de Regulação de Vagas (Sisreg) e da 'confusão territorializada' que se apresenta, por vezes, na existência de usuários ainda desorientados em meio ao acompanhamento à saúde no CMS ou na Clínica da Família. Outros questionamentos são referentes ao porquê de não poderem ter sua saúde acompanhada integralmente em hospitais terciários.

Partindo da percepção do baixo nível de informação de muitos dos usuários da unidade de saúde da família em questão, um dentista e uma enfermeira resolveram criar um espaço de troca de informações e saberes sobre o funcionamento da ESF. 
Para realização de tal atividade, a estratégia de convocação dos usuários foi por meio dos Agentes Comunitários de Saúde (ACS). Eles foram solicitados a identificar entre a população cadastrada pessoas que tivessem alguma representatividade social na comunidade, que tivessem um perfil de multiplicador de informação. Foram deixados claros os objetivos da reunião desde o convite feito pelo ACS, uma vez que havia a preocupação dos usuários concluírem ser um grupo para discutir o processo de trabalho da unidade mencionada.

Outro método também utilizado para convocação dos usuários foi a divulgação do convite nas reuniões de equipes da unidade e no fórum de gestores, que ocorrem mensalmente com vistas a reunir representantes de dispositivos sociais importantes na comunidade, como a Unidade de Polícia Pacificadora (UPP), escolas e creches, Associação e moradores, ONGs e outras unidades de saúde do território.

Além da divulgação do grupo, o planejamento da condução da atividade a ser desenvolvida envolveu os ACS, que, por serem também parte da comunidade, puderam contribuir de modo essencial para a organização e execução da atividade.

Os temas foram separados de modo a atender os assuntos de maior polêmica na comunidade local, tais como: atendimento generalista, o papel do enfermeiro na ESF, a territorialização e a organização do processo de referência e contrarreferência na rede de atenção, tendo a equipe de saúde da família como ordenadora desse sistema. Para isso, o encontro iniciaria com uma breve reflexão de como a saúde era ofertada no âmbito nacional antes da instituição do SUS, perpassando o advento do SUS, seus princípios e diretrizes.

Foram planejados dois momentos de discussão em roda de conversa. Para o primeiro momento, foi elaborada uma sucessão de sete perguntas simples que teriam por finalidade 'disparar' os temas a serem abordados a partir do protagonismo dos usuários:
1 - Como era antes do SUS?

2 - Quando ele passou a existir?

3 - Quais os princípios que dão base ao funcionamento do SUS na opinião de vocês?

4 - De onde surgiu a ESF?

5 - Por que ela surgiu?

6 - Para que ela surgiu?

7 - Com base em que a ESF desenvolve assistência à saúde?

No segundo momento, o objetivo foi discutir o conceito de Clínicas de Família a partir de três pontos-chave:

1 - Diferenciando a Clínica da Família da Unidade de Pronto Atendimento (UPA);

2 - Discutindo conceito de territorialização;

3 - Trocando ideias sobre o que vem a ser um atendimento integral.

As perguntas e os pontos-chave foram apresentados em slides de modo a direcionar as discussões geradas.

\section{Operacionalização do grupo}

Nos encontros, compareceram cerca de $50 \%$ do número de usuários convidados. Foram feitos dois encontros com dois grupos diferentes, em um intervalo de um mês, totalizando 20 usuários participantes (dez usuários em cada encontro).

O encontro começou com uma roda de apresentação, seguindo da exposição dos objetivos do grupo.

Com a pergunta 'Como era antes do SUS?', foi iniciada uma conversa sobre 
como era a assistência à saúde antes da instituição do SUS. Nesse momento, houve participação ativa dos idosos presentes, que falaram um pouco da vivência em um sistema de saúde seletivo e não universal. Uma rica experiência também foi compartilhada por um idoso nordestino após a enunciação da questão 'de onde surgiu a ESF?' Ele compartilhou com todo o grupo a história da origem das raízes da ESF em sua terra. Essa riqueza encontrada na troca de experiência reforça a ideia de Paulo Freire no sentido de não somente respeitar, mas também de aproveitar as experiências trazidas dentro de cada um (FREIRE, 2002).

A partir dessas vivências, foi apresentado então o cenário de atenção à saúde, hoje no Brasil, baseado nos princípios da universalidade, integralidade, descentralização e regionalização da rede, além dos conceitos de longitudinalidade e equidade. Esses significados foram explanados usando exemplos práticos de situações cotidianas das unidades básicas de saúde para que todos conseguissem compreender o significado de cada conceito a partir da visualização da aplicabilidade prática de cada um deles.

Foi discutida a diferença do modelo de atenção focado na promoção da saúde e do modelo que prioriza o foco nas doenças. Esse entendimento sobre a promoção da saúde foi facilitado de alguma maneira pelo fato deles poderem vivenciar na unidade frequentes atividades de promoção à saúde. Por exemplo: a estrutura física e de trabalho da Clínica da Família em questão conta com o funcionamento de grupos de convivência, como o grupo de idosos que realiza passeios, festas e comemorações; a Academia Carioca, que é um programa centrado na inserção da prática de atividade física regular em unidades de $\mathrm{AB}$ à saúde, com supervisão do educador físico; um espaço destinado à escovação supervisionada, onde a equipe de saúde bucal desenvolve as ações coletivas, entre outras atividades que contribuíram, positivamente, para que os usuários participantes pudessem visualizar as práticas de prevenção da doença e promoção da saúde.

Nesse sentido, pode-se afirmar que "as palavras a que falta corporeidade do exemplo, pouco ou quase nada valem" (FREIRE, 2002, P. 16), por isso a importância de se ter um trabalho estruturado na unidade de saúde, antes que se inicie um grupo de educação popular com objetivo de discutir o funcionamento da ESF, com base no que propõe as políticas públicas de saúde.

Foi também inserida ainda na discussão a importância do vínculo profissional-usuário na possibilidade da construção de um atendimento personalizado, mediante o convívio do profissional de saúde com a comunidade, compartilhando da mesma realidade.

Dessa forma, os usuários abriram espaço para enfatizar a essencialidade da figura do ACS e das visitas domiciliares para o êxito no acompanhamento de saúde da população adscrita. O trabalho do ACS foi posicionado pelos usuários como diferencial nesse modelo de prestação de serviços na $A B$, e assim foi explicada a importância da territorialização na organização do processo de trabalho das equipes e na oferta dos serviços na ESF.

A partir da interrogação 'Com base em que a ESF desenvolve assistência à saúde?', foram abordadas questões, como atendimento por profissional generalista $\mathrm{e}$ consultas de enfermagem (temas ainda bastante polêmicos), apresentando aos usuários a existência dos cadernos de $\mathrm{AB}$, protocolos nacionais e municipais, inclusive o Protocolo de Enfermagem na Atenção Primária à Saúde, do Rio de Janeiro, que respaldam e orientam as ações desses profissionais.

As reuniões se encerraram com a proposta de os usuários participantes levarem a discussão aos espaços já existentes na comunidade com potencial de multiplicação da informação. Foram sugeridas as reuniões de condomínios, as reuniões de pais das creches 
e escolas locais, reuniões na Associação de Moradores, entre outros espaços, entendendo que o trabalho 'extra-muros' muitas vezes obtém maior alcance.

\section{Reflexões acerca da experiência do grupo}

O primeiro desafio do profissional que se debruça na Educação Popular em Saúde é desenvolver empatia, ou seja, se colocar no lugar do usuário para poder compreender os fatos da forma como ele os entende. É enxergar o sistema de saúde, conforme se conhece, pelas lentes da comunidade local. Lentes essas formadas de experiências individuais e coletivas.

Ficou muito claro que se os profissionais de saúde conseguissem escutar os questionamentos dos usuários, por meio de 'ouvidos leigos', conseguiriam entender suas inquietações por vivenciar um sistema de saúde que vem sofrendo uma série de mudanças na conformação da oferta de serviços. Entretanto, ao se apropriar da 'responsabilização de cor-responsabilizá-los', percebe-se a necessidade da criação desses espaços em que a partir da troca de informações e saberes sobre o SUS se é mais capaz de consolidar cuidados mais efetivos e gestões mais democráticas. Afinal, "a luta para transformar o descrito em nossa Constituição em uma realidade acessível para toda a sociedade é plano para todos os sujeitos sociais" (FONSECA ET AL., 2012, P. 458).

Ao se observar cada mudança na organização da Rede de Atenção à Saúde, percebe-se que tem conquistas evolutivas as quais fortalecem a consolidação de um sistema de saúde universal, equânime, integral e resolutivo. Desse modo, não são os redirecionamentos estratégicos de uma política pública que trazem insatisfação e tensão aos cidadãos, na maioria das vezes, é simplesmente a maneira como são inseridos na vida da população. É compreensível entender, por exemplo, que uma usuária anteriormente acompanhada em um CMS há mais de 20 anos com a mesma médica ginecologista sinta alguma revolta ao descobrir que daqui para frente não poderá mais ter essa profissional enquanto referência para seu acompanhamento de saúde, mas é inaceitável perceber que essa mesma usuária não faça ideia da finalidade desse novo espaço de coexistência das ações curativas, preventivas, de promoção e de acompanhamento de saúde por uma equipe que se insere na sua comunidade e passa a fazer parte dela, cuidando integralmente de sua saúde e de sua família.

Enquanto profissionais da ESF, pode-se ter indivíduos que concordem ou não com os modos de organização da oferta dos serviços de saúde à sua comunidade, mas não se pode normalizar o fato de haver indivíduos adscritos no território que não entendem esta dinâmica dos serviços e, portanto, não se veem como corresponsáveis no sistema. Assim, pode-se afirmar que: "Constatando, nos tornamos capazes de intervir na realidade, tarefa incomparavelmente mais complexa e geradora de saberes do que simplesmente a de nos adaptar a ela" (FREIRE, 2002, P. 30).

Para que haja êxito na organização dos processos de trabalho das equipes de saúde da família e da própria unidade como um todo, a preocupação com o saber do usuário sobre a estratégia é de extrema relevância, pois se os serviços são pensados para pessoas que não compreendem suas finalidades, parece não haver muito sentido no que se faz.

A corresponsabilidade gerada em espaços democráticos como esse aponta para a desconstrução, entre profissionais e usuários, do que Barreto et al. (2012) denominam de fosso cultural, capaz de gerar grande impacto na organização dos serviços.

Para que se consiga alcançar a existência de uma realidade que usuários compreendam os objetivos de cada fluxo de atendimento na rede de atenção à saúde, é fundamental que profissionais da saúde assumam esse papel de multiplicadores de informação, principalmente no âmbito da ESF. 


\section{Considerações finais}

Conclui-se que é a partir de experiências como essa que o trabalho na ESF ganha visibilidade no meio em que é mais essencial para o desenvolvimento de tal política: a própria comunidade. O trabalho desenvolvido reafirmou a percepção acerca do baixo conhecimento existente entre os usuários do SUS a respeito da ESF e propiciou a vivência do grande potencial de um grupo de educação em saúde em que há espaço para o sujeito aprender, ensinar, ser escutado e se posicionar. Esse potencial se concretiza no poder de mudanças nas lentes pelas quais os sujeitos passam a enxergar a dinâmica de funcionamento da ESF a partir do conhecimento construído sobre ela.

Os encontros motivaram muitas reflexões dos profissionais e muitos retornos positivos dos usuários a posteriori, com solicitação do grupo de educação popular ser realizado em outros espaços da comunidade onde moradores locais entendiam ser importante.

Propõe-se a realização de grupos como esse nas unidades de saúde da família, para ampliação do acesso às informações e troca de saberes entre profissionais e usuários do sistema de saúde sobre a ESF.
Destaca-se a importância de o desenvolvimento dos grupos ocorrerem em conformidade com a cultura local específica de cada comunidade, abrindo um espaço no qual seja valorizado o saber dos indivíduos. Destaca-se, ainda, a importância de haver um adequamento na linguagem a ser usada e a predominância da concepção de que o cuidado em saúde perpassa o direito à informação. Além disso, é preciso que se aproprie da ideia de que do diálogo em que se desafia um grupo popular a pensar sua história social como experiência comum a seus membros, emerge a "necessidade de superar certos saberes que desnudados, vão mostrando sua incompetência para explicar os fatos" (FREIRE, 2002, P. 32).

Por isso, é necessário que haja profissionais comprometidos com o processo de Educação Popular em Saúde, para que haja usuários que compreendam o funcionamento da rede local de atenção à saúde e que entendam a importância do vínculo à sua equipe de saúde da família. Isso porque, a partir daí, serão alcançados melhores resultados no que tange ao próprio acompanhamento dos indivíduos, à dinâmica de funcionamento da unidade de saúde da família e ao fortalecimento do controle social.

\section{Referências}

BARRETO, I. C. H. C. et al. Gestão Participativa do SUS e a integração entre ensino, serviço e comunidade: a experiência da Liga de Saúde da Família, Fortaleza, CE. Saúde Soc., São Paulo, v. 21, n. 1, p. 80-93, 2012. Disponível em: <http://www.scielo.br/pdf/sausoc/ v21s1/07.pdf >. Acesso em: 12 set. 2013.

BONETTI, O. P.; PEDROSA, J. I. S.; SIQUEIRA, T. C. A. Educação Popular em Saúde como Política do Sistema único de Saúde. Rev. APS., Juiz de Fora, v. 14, n. 4, p. 397407, 2011. Disponível em: <http://aps.ufjf.emnuvens.com. br/aps/article/view/1607/551>. Acesso em: 18 fev. 2015.
BRASIL. Lei n. 8080 de 19 de setembro de 1990. Dispõe sobre as condições para a promoção, proteção e recuperação da saúde, a organização e o funcionamento dos serviços correspondentes e dá outras providências. Diário Oficial [da] União, Brasília, DF, 1990. Disponível em: <http://portal. saude.gov.br/portal/arquivos/pdf/lei8080.pdf > Acesso em: 12 set. 2013.

Ministério da Saúde e Conselho Nacional de Saúde. Carta dos direitos dos usuários da saúde. 3. ed. Brasília, DF: Ministério da Saúde, 2009. 
Ministério da Saúde e Secretaria de Gestão Estratégica e Participativa. Caderno de Educação Popular em Saúde. Brasília, DF: Ministério da Saúde, 2007. (Série B, Textos Básicos de Saúde).

FONSECA G. S. et al. Percepção de usuários e profissionais de saúde sobre o Sistema Único de Saúde no município de Santa Cruz- RN. Rev. bras. promoç saúde, Fortaleza, v. 25, n. 4, p. 455-461, 2012. Disponível em: <http://ojs.unifor.br/index.php/RBPS/article/view/2548>. Acesso em: 15 fev. 2015.

FREIRE, P. Pedagogia da Autonomia: saberes necessários a prática educativa. 25. ed. São Paulo: Paz e Terra, 2002.

MENDES, E. V. Uma agenda para a saúde.

São Paulo: Hucitec, 1996.

PEDROSA, J. I. S.; PEREIRA, E. D. S. Atenção Básica e o controle social em saúde: um diálogo possível e necessário. Rev Brasileira de Saúde da Família, Brasília, DF, v. 8, n. especial, p. 7-22, 2007.
RODRIGUES, R. D.; ANDERSON, M. I. P. Saúde da Família: uma estratégia necessária. Rev bras med fam comunidade, Florianópolis,v. 6, n. 18, p. 21-24, 2011. Disponível em: <http://www.rbmfc. org.br/index.php/rbmfc/article/view/247/196>. Acesso em: 11 abr. 2013.

ROLIM, L. B.; CRUZ, R. S. B. L. C.; SAMPAIO, K. J. A. J. Participação popular e controle social como diretriz do SUS: uma revisão narrativa. Saúde em Debate, Rio de Janeiro, v. 7, n. 96, p. 139-147, 2013. Disponível em: <http://www.scielo.br/pdf/sdeb/v37n96/16.pdf > Acesso em: 1 ago. 2015.

STARFIELD, B. Atenção Primária: equilíbrio entre necessidades de saúde, serviços e tecnologia. Brasília, DF: Unesco, Ministério da Saúde, 2002.

Recebido para publicação em março de 2015

Versão final em setembro de 2015

Conflito de interesses: inexistente

Suporte financeiro: não houve 